\title{
Cortical auditory disorders: clinical and psychoacoustic features
}

\author{
MARIO F MENDEZ, * GEORGE R GEEHAN, Jr.† \\ From the Department of Neurology, Case Western Reserve University, Cleveland, Ohio,* and the Hearing and \\ Speech Center, Rhode Island Hospital†, Providence, Rhode Island, USA
}

SUMMARY The symptoms of two patients with bilateral cortical auditory lesions evolved from cortical deafness to other auditory syndromes: generalised auditory agnosia, amusia and/or pure word deafness, and a residual impairment of temporal sequencing. On investigation, both had dysacusis, absent middle latency evoked responses, acoustic errors in sound recognition and matching, inconsistent auditory behaviours, and similarly disturbed psychoacoustic discrimination tasks. These findings indicate that the different clinical syndromes caused by cortical auditory lesions form a spectrum of related auditory processing disorders. Differences between syndromes may depend on the degree of involvement of a primary cortical processing system, the more diffuse accessory system, and possibly the efferent auditory system.

Since the original description in the late nineteenth century, a variety of disorders has been reported from bilateral lesions of the auditory cortex and its radiations. The clinical syndrome of cortical deafness in a woman with bitemporal infarction was described by Wernicke and Friedlander in 1883 . $^{1}$ The term auditory agnosia was used by Freud in $1891,{ }^{2}$ and has been used alternately for two observed syndromes: a selective decrease in recognition of non-verbal sounds and a generalised decrease in recognition of both verbal and non-verbal sounds. Lissauer (1890) proposed the existence of an apperceptive agnosia resulting from inability to synthesise sensory information into an adequate percept. ${ }^{3}$ Kussmaul (1877) first described a patient with pure word deafness, ${ }^{4}$ and Bernard (1889) noted an amusia where melodies lose their musical character. ${ }^{5}$ Since that time, many other cases have been reported and attributed to lesions involving the cortical auditory areas. ${ }^{6-10}$

It is still not fully understood how dysfunction of the cortex results in these diverse syndromes and whether they are functionally related or truly distinct. ${ }^{3}$ Investigators disagree as to whether true deafness can result from cortical lesions. ${ }^{61112}$ Case

Address for reprint requests: Mario F Mendez. M.D., Department of Neurology, University Hospitals of Cleveland. 2074 Abington Road. Cleveland, Ohio 44106, USA.

Received 6 March 1987 and in revised form 19 June 1987. Accepted 26 June 1987 reports of auditory "agnosias" suggest that these are not genuine agnosias in the classic Teuber definition of an intact percept "stripped of its meaning". 1314 Other studies indicate that pure word deafness and the auditory agnosias may be functionally related auditory perceptual disturbances. ${ }^{15-17}$ In addition, the clinical evolution and substantial overlap between these disorders suggest that these are related disorders and should have similar underlying psychoacoustic abnormalities.

A review of the clinical characteristics and psychoacoustic findings of the cortical auditory disorders clarifies whether these are a spectrum of related disorders. We investigated two new patients whose condition evolved from "cortical deafness", absent response to sound with decreased hearing thresholds, to disturbances of sound recognition. We used evoked responses and psychoacoustic tests and compared our findings with all similarly studied cases in the literature. These findings suggested a model of dysfunction of the auditory cortex.

\section{Case reports}

Case 1 A 60 year old, right-handed male with previously normal hearing, was reported to have a sudden onset of deafness of 2 weeks duration. On admission, he did not respond to verbal questions or environmental sounds and did not startle to loud noises. He was an alert patient with fluent speech and occasional literal paraphasias. He spoke in a hypophonic monotone. Testing of recent memory, constructions, and calculations was within normal limits. 

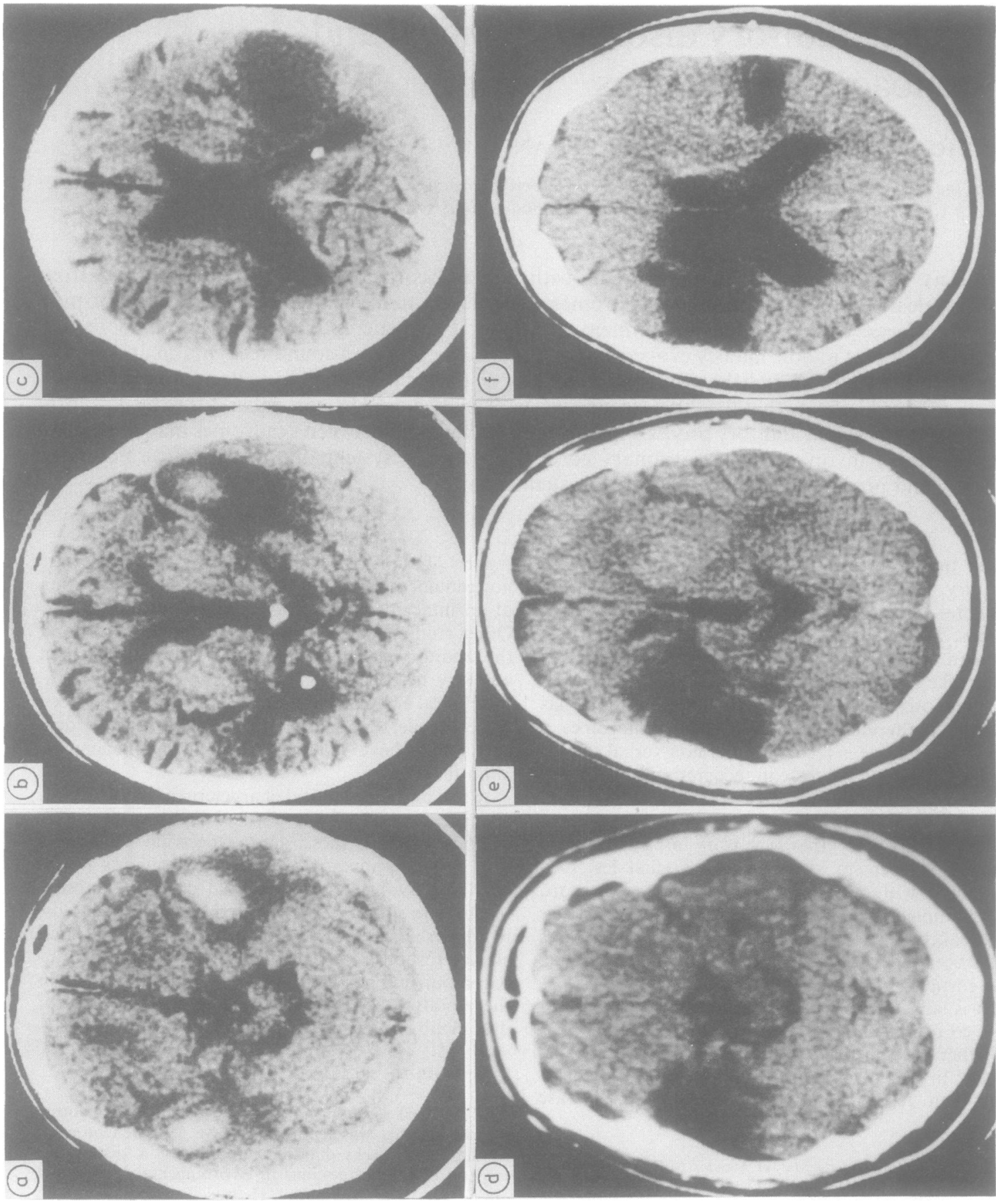

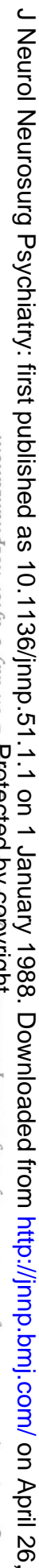

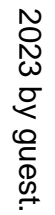


Initial evaluation was consistent with the impression of cortical deafness. Past medical history included hypertension, a myocardial infarction, and a right hemisphere lacunar stroke 4 years previously. Examination was remarkable for left-sided increased tone, hyperreflexia, and an extensor plantar response all dating from his prior stroke. $\mathrm{He}$ had multiple small necrotic lesions on his fingertips of possible embolic origin. The non-contrast CT scan showed bilateral haemorrhagic infarcts in both temporal lobes involving the superior temporal gyri and surrounding hypodensity from temporal tips to parietal lobes (fig la, b, c). Echocardiography demonstrated a dyskinetic ventricular segment, and the patient was subsequently given anticoagulants for a possible cardiac embolic source.

During his first 2 weeks in the hospital, there was contradictory evidence of deafness. Audiological testing found pure tone thresholds to be $70 \mathrm{~dB} \mathrm{HL}$, above which responses were inconsistent. The patient appeared to be unaware of sound; however, he occasionally and unexpectedly reacted to sounds that he could not hear later. This phenomenon was unreproducible on testing. Furthermore, he stated that he could not hear, but did not behave like other deaf patients by requesting the speaker to speak louder, repeat himself, write things down, nor did he tilt an ear toward the speaker as in intent listening. These reactions did not correlate with sounds that were soft or loud, simple or complex.

After 2 weeks, his awareness of sounds was consistent. Pure tone thresholds were $30-40 \mathrm{~dB}$ in the right ear, and $20-25 \mathrm{~dB}$ in the left ear, but with continued variability in his responses. He did not differentiate voices, music, and environmental sounds. Everything sounded like a disagreeable noise, a "hurr," including the pure tone signals. He did not startle to loud noises or localise sound. Efforts to hear led to the erroneous interpretation of sounds from concurrent environmental cues.
At 6 weeks he had a mild fluent aphasia with acoustically similar paraphasic errors on naming: chisners/scissors, whiskle/whistle, trifloss/tripod. Verbal repetition was severely defective with phonemic substitutions and selfcorrections by acoustic approximations. Reading and writing were relatively preserved. After resolution of the haemorrhage and oedema, a CT scan at 3 months showed smaller lesions involving the superior temporal gyri bilaterally (fig 2a, b).

Case 2 A 23 year old ambidextrous male, after an episode of altered awareness, was brought to the emergency room where he had a generalised tonic-clonic seizure. After becoming alert, he behaved as if totally deaf. He attended visually, but did not follow oral commands or respond to environmental sounds. Verbal output was loud and fluent with literal paraphasias, perseveration, and word-finding difficulty. He comprehended written and gestural communication. Recent memory, constructions, or calculations were normal.

Seventeen months previously, he had suffered a stroke resulting in left hemiparesis. He had left arm weakness, spasticity, hyperreflexia, and an extensor plantar response. The CT scan showed an old right frontoparietotemporal infarct and a new left parietotemporal lesion (fig ld, e, f). Echocardiogram revealed an unusual configuration of the posterior mitral valve leaflet with vegetations and a dilated left ventricle. The patient was heparinised and eventually discharged on phenytoin and coumadin for a presumed cardiac embolic source.

During the first 3 weeks of his hospitalisation, there was evidence of deafness. He had no response at output limits of audiometry and showed no discomfort to high sound intensities. However, he occasionally had inconsistent and unexpected responses to environmental sounds. He did not
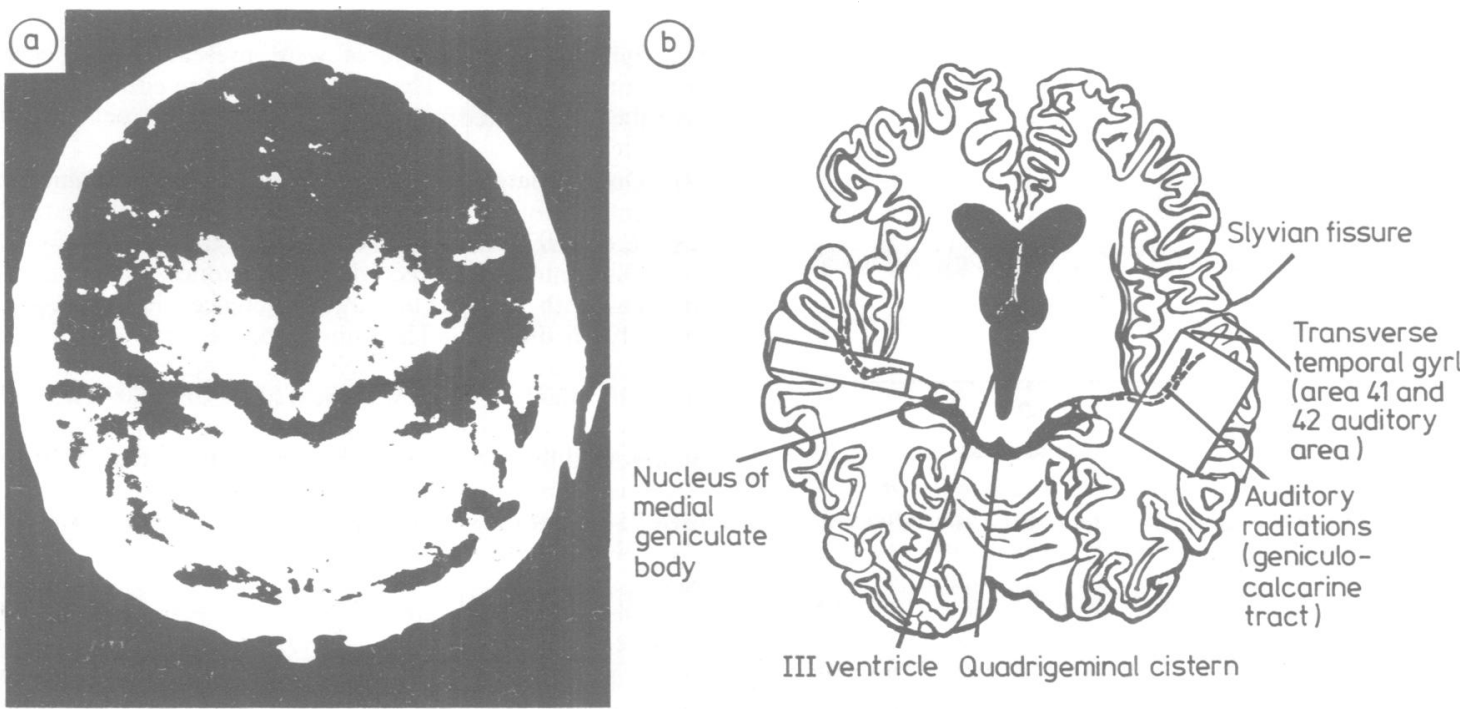

Fig 2 (a) CT scan of case 1 three months after his strokes. (b) Schematic drawing at the same horizontal level of the brain showing the central auditory structures involved. 
ask examiners to raise their voices, or repeat their message, write things down, nor did he appear concerned about his inability to hear.

After 3 weeks he began to hear sound consistently. Audiograms showed a mild sensorineural hearing loss but with much variability in his responses (fig 3a). All sounds were like a "buzzing noise." Melodies were not recognised, the startle response was decreased and sound localisation was poor. At 2 months, he recognised many environmental sounds, but not speech or music; at 3 months, music recognition returned but speech lagged; and after 7 months, there was significant language comprehension.

Language evaluation a year later revealed a mild highlevel deficit in auditory comprehension and relatively preserved fluency, reading, and writing. An initial anomia had

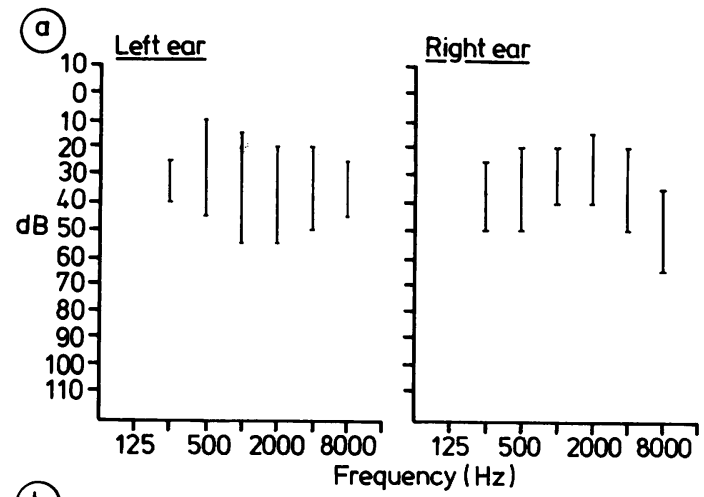

(b)



Fig 3 (a) Summary of pure tone audiograms of case 2 from 2-18 months after his second stroke and after he stopped showing progressive improvement in hearing thresholds. The audiograms showed a variable and fluctuating hearing loss. Hearing levels are in $d B$ (ANSI. 1969). (b) Middle latency response testing of case 2 showing complete absence of responses after $20 \mathrm{~ms}$. The characteristic Pa wave should occur at 30-35 ms. The Po response is probably myogenic from the postauricular muscle. improved to near normal, and repetition showed occasional phonemic substitutions with self-correction with acoustic approximations.

\section{Methods}

Evoked responses Stimuli were presented at approximately 90 dB HL via shielded headphones.

(1) Case 1 Brainstem auditory evoked response (BAER) variables were: $10 \mathrm{~ms}$ epoch, $102 \mu \mathrm{s}$ rarefaction clicks, rate of $10 \mathrm{~Hz}, 2048$ repetitions and bandpass of $160-3200 \mathrm{~Hz}$. Middle latency response (MLR) variables were: $50 \mathrm{~ms}$ epoch, $1 \mathrm{KHz}$ tone bursts of $5 \mathrm{~ms}$, rate of $10 \mathrm{~Hz}, 1024$ repetitions and bandpass of $0 \cdot 8-3200 \mathrm{~Hz}$. Late vertex auditory evoked response (LVAER) variables were: $300 \mathrm{~ms}$ epoch, $1 \mathrm{KHz}$ tone bursts of $50 \mathrm{~ms}$, rate of $0.5 \mathrm{~Hz}, 300$ repetitions and bandpass of $0.8-160 \mathrm{~Hz}$.

(2) Case 2 BAER variables were: $10 \mathrm{~ms}$ epoch, $102 \mu \mathrm{s}$ rarefaction clicks, rate of $31 \cdot 1 \mathrm{~Hz}, 2048$ repetitions and bandpass of $300-1500 \mathrm{~Hz}$. MLR variables were: $100 \mathrm{~ms}$ epoch, $102 \mu \mathrm{s}$ rarefaction clicks, rate of $11 \cdot 1 \mathrm{~Hz}, 2000$ repetitions and bandpass of $0.8-1500 \mathrm{~Hz}$. The evoked responses were recorded from $\mathrm{Cz}$ ("10-20" System) referred to the ipsilateral mastoid with the contralateral mastoid electrode used as a ground.

Psychoacoustic tests Pilot controls were tested at the identical settings described below for the patients and scored $100 \%$ correct on these psychoacoustic tests. Examination of attention span, language, visual fields, and hearing acuity did not reveal abnormalities that would interfere with these tasks. The testing sessions were limited to 30 minutes. Instructions were given in writing, and two or more trials were administered until the patients understood the tasks. All auditory stimuli were presented binaurally by loudspeakers located 2 feet from the patient. The patients were asked to:

(1) Listen to 48 pre-recorded environmental sounds and point to the corresponding picture, based on similar testing by Vignolo. ${ }^{18}$ Four pictures were presented with each environmental sound. The four choices were either correct, acoustically related, semantically related, or totally unrelated.

(2) Discriminate two environmental sounds as same or different by pointing to one of two response cards marked $S A M E$ or DIFFERENT. There were 10 trials.

(3) Discriminate pre-recorded pure tones as same or different with respect to large differences in frequency, intensity, or duration. The same response cards were used, and there were 10 trials on each task. Parameters, when not an independent variable, were held at $60 \mathrm{~dB}, 1000 \mathrm{~Hz}$, and $250 \mathrm{~ms}$. Frequencies ranged from 250 to $3000 \mathrm{~Hz}$ with a minimum difference of $1000 \mathrm{~Hz}$, intensity test used 70 to $90 \mathrm{~dB}$ with a minimum difference of $10 \mathrm{~dB}$, and duration test used 75 to $300 \mathrm{~ms}$ with a minimum difference of $150 \mathrm{~ms}$.

(4) Discriminate as same or different between 10 phoneme pairs.

(5) Discriminate as same or different between pairs of sequences of three sounds which varied in regularity, in frequency pattern, or in vowel sequence. In the first 10 trials, the three sounds were spaced apart at regular intervals of from 50-300 ms. The patients had to distinguish between sequences varying only in a regular interstimulus interval. In 
the second 10 trials, the patients had to distinguish between sequences with variable interstimulus intervals between the three stimuli. In the third and fourth sets, they were spaced at regular intervals of $150 \mathrm{~ms}$ but were composed of different frequencies or different vowel sounds.

\section{Results}

Evoked responses In Case 1, evoked response testing at 6 weeks showed normal BAER but absent MLR and LVAER. In Case 2, evoked responses showed normal BAER and an absent Pa wave of the MLR on seven occasions (fig 3b).

Psychoacoustic tests Case 1 was tested at 3 months after stroke and Case 2 two years after the onset of his cortical auditory disturbance.

(1) Identification of pre-recorded environmental sounds: Case 1 identified 19 of 48 sounds correctly, that is, no better than chance. Of the 29 error responses, 14 were acoustically related ( $48 \%)$, seven were semantically related $(24 \%)$, and eight were totally unrelated $(27 \%)$. Case 2 did significantly better but still missed seven out of the 48 environmental sounds. Most of his errors were also acoustically related (five out of seven). His acoustic errors were mistaking church bells for a telephone, an airplane for a motorcycle, water for "slurping," clapping for someone running, and a hand bell for a telephone. These patients responded best to cuing that clarified characteristics of the sound: Case 1 identified five of the previously missed environmental sounds when given silent lip reading cues. Written class cues such as "an animal," "a musical instrument," etc., did not help on a single occasion. Silent lip reading also facilitated sound recognition in Case 2 while written class cues allowed him to "figure it out" and did not provide a sense of familiarity for the sound.

(2) Discrimination between two environmental sounds: Case 1 succeeded in only four out of 10 trials, no better than chance. Case 2 was able to match environmental sounds to each other in all 10 trials but did so with uncertainty and hesitations.

(3) Discrimination of pure tones based on frequency, intensity, or duration: Case 1 performed no better than chance: $5 / 10,5 / 10,5 / 10$, respectively; however, Case 2 did well on these tasks: 10/10 on frequency discrimination, $8 / 10$ on intensity discrimination (binomial $\mathrm{p}=0.044$ ), and $8 / 10$ on duration discrimination $(\mathrm{p}=0.044)$.

(4) Differentiation between phonemes: Case 1 did poorly on both vowels $(5 / 10)$ and voiced versus voiceless consonants $(4 / 10)$, but Case 2 did poorly only on the latter (7/10). Case 2 got 10/10 for vowels.

(5) Discrimination between different sequences of sounds: both patients did significantly worse on sequences varying in regularity, frequency, or vowels.
Case 1 distinguished pure tones with constant interstimulus intervals (10/10), but failed to distinguish them when the intervals varied $(5 / 10)$. Scores on a frequency pattern and a sequence of vowels were 5/10 and 6/10, respectively. Case 2 had the Pinhiero Pitch Pattern Sequence ${ }^{19}$ (verbal part) administered at 7 months with a $30 \%$ correct response, and at 18 months with $30 \%$ in the left ear and $60 \%$ in the right (20\% is chance level). When temporal sequencing skills were tested at 2 years, he answered $10 / 10$ for pure tones with constant interstimulus intervals and $7 / 10$ for tones with variable intervals. On a frequency sequence test he answered $6 / 10$, and on a vowel sequence test he answered $7 / 10$ correctly.

\section{Discussion}

We studied two new cases of auditory cortical disorder which differed in degree of recovery. Our first patient went from cortical deafness to a generalised auditory agnosia, and our second patient evolved further into a word deafness plus amusia stage, a pure word deaf stage, and finally a mild disturbance primarily in temporal pattern analysis. On clinical examination, both had marked overlap of features between the different cortical auditory syndromes, dysacusis or the experience of sound as distorted and/or disagreeable, and absent middle latency evoked potentials. On psychoacoustic tests they showed predominant acoustic errors or evidence that sounds were mistaken because of disturbance of their auditory characteristics, inconsistent auditory behaviours such as unexpected responses to specific isolated sounds despite otherwise compromised auditory functioning, and a similar pattern of decreased discrimination of acoustic parameters, particularly in temporal sequencing.

Other patients with cortical auditory disorders have comparable findings. Reports show a similar pattern of evolution starting with a transient cortical deafness and evolving through various stages to the other cortical auditory disorders. ${ }^{15-20}$ There is significant clinical overlap across these syndromes, that is, they are rarely "pure" disturbances. ${ }^{15}$ Some decrease in auditory acuity is found in patients with agnosia or bilateral word deafness, ${ }^{1} 1222122$ and environmental sound agnosia is present, to a degree, in cortical deaf and bilateral word deaf cases. ${ }^{623-26}$ In bilateral pure word deaf cases there may be psychoacoustic deficits like those of the auditory agnosias. ${ }^{16172829}$ Finally, amusia is rarely reported to occur alone and is frequently combined with pure word deafness. ${ }^{30}$

Many authors have reported dysacusis. Sounds may be experienced as altered and may even sound like a foreign language. Our patients described sound as a disagreeable "hurr" or a buzzing noise. 
Table 1 Middle latency evoked potentials

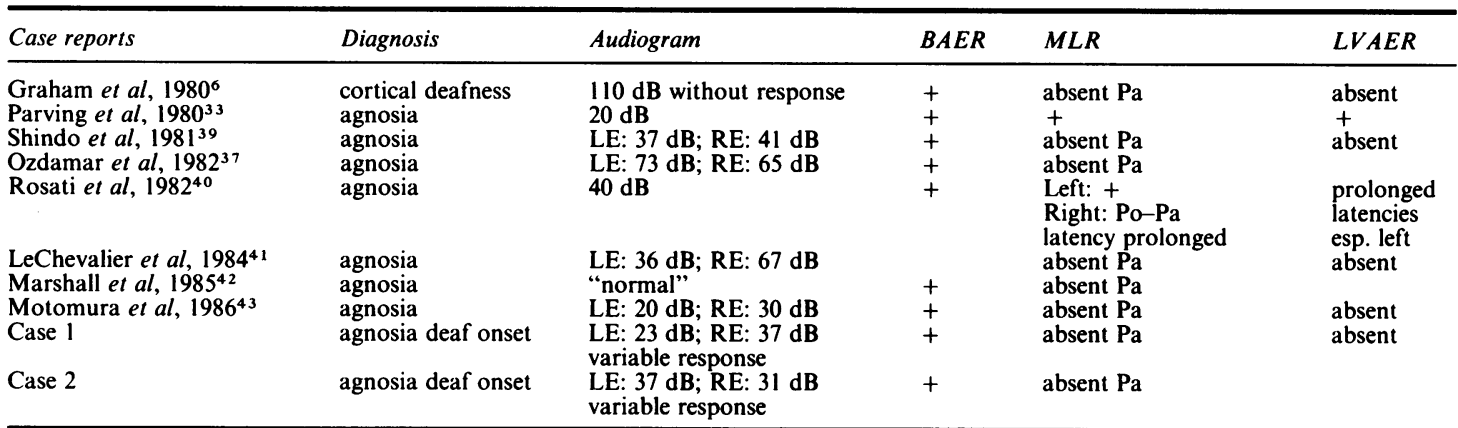

$+=$ present; - = absent; LE = left ear; RE = right ear; where given separately for each ear, audiogram values correspond to pure tone averages for the speech range $(500,1000,2000 \mathrm{~Hz})$; agnosia refers to all sound recognition disorders such as auditory sound agnosia, word deafness, or amusia. The characteristic Pa wave should occur at $30-35 \mathrm{~ms}$. The Po response is probably myogenic from the postauricular muscle.

Sound has been described as "banging of tin cans", 31 "rattles and squeaks", 32 "buzzing and roaring", 33 "far away", ${ }^{23}$ "doubled", 34 "excessively loud", 21 or sometimes so bothersome as to require wearing earplugs. ${ }^{16}$

Recently, diagnostic tests have focused on the auditory middle latency evoked responses, occurring between 10 and $50 \mathrm{~ms}$ after the auditory stimulus, as a possible discriminative test for these syndromes. ${ }^{35} 36$ While most patients with cortical auditory disorders have normal brainstem evoked responses and abnormal late vertex or "cortical" evoked responses, ${ }^{37}$ it is suggested that the absence of the $\mathrm{Pa}$ wave of the MLR is uniquely characteristic of cortical deafness and not seen in agnosic sound disturbances. ${ }^{38}$ However, the $\mathrm{Pa}$ wave, which may come from thalamic nuclei, lemniscal pathways, or the accessory cortical auditory areas, ${ }^{35}$ was absent in both of our cases. It was also absent in most other patients reported in the literature regardless of specific cortical auditory disorder or audiographic findings (table 1) $6333739-43$ including a case with bilateral subcortical lesions $\mathrm{s}^{43}$ and does not clearly discriminate between the cortical auditory disorders.

On psychoacoustic testing a similar pattern of deficits is found among the different cortical auditory syndromes. First, errors in sound recognition occur because acoustic characteristics are not deciphered. This is evidenced by the inconsistency in matching identical environmental sounds and the presence of phonemic substitutions on attempting to reproduce sounds. On repeating sounds there may be a conduite

Table 2 Perceptual findings in cortical auditory disorders

\begin{tabular}{|c|c|c|c|c|c|c|c|}
\hline \multirow[b]{2}{*}{ Case reports } & \multirow[b]{2}{*}{ Audiogram } & \multirow{2}{*}{$\begin{array}{l}\text { Acoustic- } \\
\text { type errors }\end{array}$} & \multirow{2}{*}{$\begin{array}{l}\text { Consistency } \\
\text { of sound percept } \\
\text { matching }\end{array}$} & \multicolumn{3}{|c|}{$\begin{array}{l}\text { Acoustic } \\
\text { discrimination }\end{array}$} & \multirow{2}{*}{$\begin{array}{l}\text { Temporal } \\
\text { sequencing }\end{array}$} \\
\hline & & & & freq. & int. & $d u r$. & \\
\hline 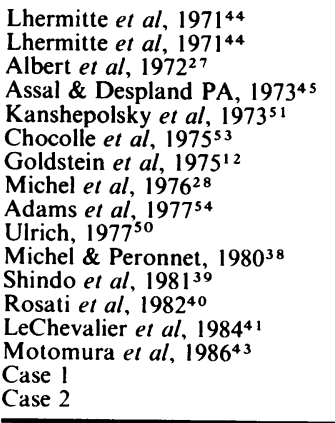 & $\begin{array}{l}\text { LE: } 11 \mathrm{~dB} \text { RE: } 17 \mathrm{~dB} \\
\text { LE: } 63 \mathrm{~dB} \text { RE: } 53 \mathrm{~dB} \\
\text { LE: } 24 \mathrm{~dB} \text { RE: } 20 \mathrm{~dB} \\
\text { no significant deficit } \\
\text { LE: } 37 \mathrm{~dB} \text { RE: } 33 \mathrm{~dB} \\
\text { LE: } 28 \mathrm{~dB} \text { RE: } 27 \mathrm{~dB} \\
70 \mathrm{~dB} \\
\text { LE: } 40 \mathrm{~dB} \text { RE: } 10 \mathrm{~dB} \\
\text { LE: } 73 \mathrm{~dB} \text { RE: } 69 \mathrm{~dB} \\
\text { inconsistent } \\
\text { LE: } 40 \mathrm{~dB} \text { RE: } 12 \mathrm{~dB} \\
\text { LE: } 37 \mathrm{~dB} \text { RE: } 41 \mathrm{~dB} \\
40 \mathrm{~dB} \\
\text { LE: } 36 \mathrm{~dB} \text { RE: } 67 \mathrm{~dB} \\
\text { LE: } 20 \mathrm{~dB} \text { RE: } 30 \mathrm{~dB} \\
\text { LE: } 23 \mathrm{~dB} \text { RE: } 37 \mathrm{~dB} \\
\text { LE: } 37 \mathrm{~dB} \text { RE: } 31 \mathrm{~dB}\end{array}$ & $\begin{array}{l}+ \\
+ \\
+ \\
+ \\
+ \\
+ \\
+ \\
+ \\
+ \\
+ \\
+ \\
+ \\
+ \\
+\end{array}$ & $\begin{array}{l}- \\
- \\
- \\
-\end{array}$ & $\begin{array}{l}+ \\
+ \\
+ \\
+ \\
+ \\
+ \\
+ \\
+ \\
+ \\
+ \\
+ \\
+ \\
+ \\
+\end{array}$ & $\begin{array}{l}+ \\
+ \\
- \\
+ \\
- \\
+ \\
+ \\
- \\
+ \\
- \\
- \\
- \\
+ \\
- \\
+ \\
-\end{array}$ & $\begin{array}{l}- \\
- \\
+ \\
- \\
- \\
- \\
+ \\
- \\
- \\
- \\
- \\
- \\
-\end{array}$ & $\begin{array}{l}- \\
- \\
- \\
- \\
+1 \\
- \\
- \\
- \\
- \\
- \\
- \\
- \\
- \\
- \\
- \\
-\end{array}$ \\
\hline
\end{tabular}


d'approche of successive acoustic approximations until the word is recognised. Foreign words and nonsense words are reproduced with difficulty. Lip reading, with its added information about the acoustic characteristics of a sound, was superior to semantic cues about sound class or context.

Secondly, patients with cortical auditory disorders have inconsistent auditory behaviour. Cortically "deaf" patients have had unexpected reactions to environmental sounds. ${ }^{11} 12244244-47$ For example, our first patient reported being disturbed by the nocturnal conversations of unseen people in the hall despite concurrent absence of any reaction to loud noise. He also displayed no reaction to a ringing telephone in a small room. Afterwards, when asked if he heard the telephone, he showed some recognition reminiscent of the blindsight recognition seen in cortical blindness. Mahoudeau reported a patient who did not experience discomfort to a $100 \mathrm{~dB}$ stimulus but could hear the soft jangling of keys or snapping of fingers, ${ }^{48}$ and LeChevalier had an unusual patient who retained a pleasure sensation to music. ${ }^{41}$ Furthermore, as patients recovered from cortical deafness, many still regarded themselves as deaf and denied hearing sounds that they reacted to or, conversely, lacked the startle response to unexpected sounds. ${ }^{11123849}$ Another instance of auditory behavioural inconsistency has been the absence of behaviours seen in those who are hard of hearing, for example, requests for clarification or attempts to understand the speaker better.

Finally, a summary of studies that have looked at psychoacoustic characteristics shows a similar pattern of disturbances across all auditory cortical syndromes (table 2). ${ }^{12272838-41444550-54}$ Ulrich in his review of 29 cases of auditory agnosia was impressed with subjects' inability to perform on specific psychoacoustic features. ${ }^{50}$ Regardless of specific cortical auditory disorder, the most common disturbances were in discriminating sound sequences, followed by sound duration. Basic frequency and intensity discrimination were better preserved.

The present findings and a review of the literature suggest that the different clinical syndromes resulting from lesions in the cortical auditory areas constitute a spectrum of related auditory processing disorders with similar clinical features and common underlying psychoacoustic abnormalities. This has not been previously established. The clinical course may reveal a pattern of improvement from a usually transient cortical deafness to generalised auditory agnosia; selective auditory agnosia, pure word deafness and/or amusia; and ultimately a residual disorder of temporal sequencing. These are not truly distinct disorders. There is much clinical overlap across syndromes, and there are absent MLRs regardless of diagnosis.
Disturbed auditory processing is evidenced by the perception of sounds as distorted and variable. Furthermore, acoustic cues and other clarifications of the sound signal may help in sound recognition; semantic cues do not. Disturbed auditory attentional mechanisms are suggested by the presence of auditory behavioural inconsistencies. Unexpected reactions to sounds indicate at least subliminal or intermittent signal reception. The lack of requests for clarification of unrecognised sounds, compromised startle response, and poor sound localisation may also be manifestations of selective auditory inattention. Disturbed temporal processing is a specific cortical auditory disturbance. A hierarchy of psychoacoustic disturbances occur, and the most vulnerable psychoacoustic processes are those which are a function of time, particularly sequencing and duration. Even stop consonants, which require temporal transitional analysis, are more likely to be abnormal compared to vowels.

When correlated with the pathology, the clinical and psychoacoustic findings suggest certain functional relationships to the auditory cortex. Cases of cortical deafness involve extensive lesions which extend subcortically,24464755 and true "cortical" deafness from isolated lesions of the cortex probably does not exist. Interhemispheric differences are not totally clear, but verbal or semantic comprehension may be mediated more by the left hemisphere and certain auditory perceptual properties more by the right. ${ }^{1856^{-59}}$ Clearly, pure word deafness may occur with isolated left hemisphere lesions, ${ }^{3}$ and amusia may be more pronounced with right hemisphere lesions. ${ }^{30}$ However, in most auditory cortical disorders a part of both the right and the left auditory cortex must be damaged for the syndrome to appear. ${ }^{2151}$

The remaining functional relationships may be explained by the extent of involvement of the primary auditory cortical system, the accessory auditory cortical system, and possibly disturbances of the efferent auditory system as well. The more complex temporal analysis needed for language and music may require the primary auditory cortex (Heschl's gyrus, area 41) and its main radiations from the medial geniculate bodies. Bilateral lesions in this main route into and from the primary auditory cortex could result in pure word deafness, amusia, or the frequent combination of pure word deafness plus amusia. ${ }^{30} 60$ This more complex temporal pattern analysis is not a requirement for the processing of most environmental sounds. Their analysis can bypass the primary auditory cortex and take place in secondary auditory association areas reached through the accessory pathways. ${ }^{6162}$ This dual organisation has been suggested to explain how primary cortex lesions can result in word deafness with relative sparing of envi- 
ronmental sound recognition, ${ }^{63}$ and, conversely, the existence of cases with abnormal environmental sound recognition but preserved language comprehension. ${ }^{2764}$ The efferent auditory system may also play a role in these disorders. Through multiple reciprocal connections with subcortical structures, it mediates specific auditory attention by suppression of unwanted sound and enhancement of the signal of choice. This system may result in much of the auditory behavioural inconsistency through exaggeration of sound suppression, for example, Miceli's and Lhermitte's patients also had no reactions to sound when engaged in other tasks. ${ }^{1445}$

In summary, patients with bilateral lesions in the cortical auditory regions manifest a spectrum of disorders ranging from cortically deaf to generalised auditory agnosia, selective auditory agnosia, pure word deafness and/or amusia, and a milder disturbance in the temporal pattern analysis of sound. The clinical evolution and overlap, the presence of dysacusis, the lack of discrimination of the MLR findings, and the similar pattern of psychoacoustic deficits indicate that these are related disturbances of auditory processing. It is suggested that clinical differences between these syndromes may depend on the degree of involvement of the primary temporal processing system, the more diffuse accessory system, the left and right hemisphere, and possibly the auditory efferent system.

\section{References}

1 Wernicke C, Friedlander C. Ein Fall von Taubheit in Folge von doppelseitiger Lasionen des Schlafenlappens. Fortschritte der Medizin 1883;1:177-85.

2 Freud S. Zur Auffassung der Aphasien. Vienna: Deuticke, 1981 (English translation, On Aphasia, London, Imago, 1953).

3 Bauer RM, Rubens AB. Agnosia. In: Heilman KM, Valenstein E, eds. Clinical Neuropsychology. New York: Oxford Univ Press 1985:209-17.

4 Kussmaul A. Disturbances of speech. In: von Ziemssen H, ed. Cyclopedia of the Practice of Medicine. New York: William Wood 1877:581-875.

5 Bernard P. De l'aphasie et de ses diverses formes. Paris: Lecrosnier et Babe, 1889.

6 Graham J, Greenwood R, Lecky B. Cortical deafness. A case report and review of the literature. J Neurol Sci 1980;48:35-49.

7 Ulrich G. Interhemispheric functional relationships in auditory agnosia. Brain Lang 1978;5:286-300.

8 Vignolo LA. Auditory agnosia: A review and report of recent evidence. In: Benton AL, ed. Contributions to Clinical Neuropsychology. Chicago: Aldine 1969:172-231.

9 Oppenheimer DR, Newcombe F. Clinical and anatomic findings in a case of auditory agnosia. Arch Neurol 1978;35:712-19.

10 Rousseaux M, Devos P. Deafness, mutism and behavioral problems caused by bitemporal cerebral lesion. Cortex 1983;4: 557-68.

11 Leicester J. Central deafness and subcortical motor aphasia. Brain Lang 1980;10:224-42.

12 Goldstein MN, Brown M, Hollander J. Auditory agnosia and cortical deafness: analysis of a case with a three-year follow-up. Brain Lang 1975;2:324-32.

13 Goldstein MN. Auditory agnosia for speech ("pure word deafness"): a historical review with current implications. Brain
Lang 1974;1:195-204.

14 Miceli G. The processing of speech sounds in a patient with cortical auditory disorder. Neuropsychologia 1982;20:5-20.

15 Buchman AS, Garron DC, Trost-Cardamone JE, Wichter MD, Schwartz M. Word deafness: One hundred years later. J Neurol Neurosurg Psychiatry 1986;49:489-99.

16 Auerbach SH, Allard T, Naeser M, et al. Pure word deafness. Analysis of a case with bilateral lesions and a defect at the prephonemic level. Brain 1982;105:271-300.

17 Albert ML, Bear D. Time to understand. A case study of word deafness with reference to the role of time in auditory comprehension. Brain 1974;97:373-84.

18 Vignolo LA. Auditory agnosia. Phil Trans $R$ Soc Lond 1982;B298:49-57.

19 Pinheiro ML, Musiek FE. Sequencing and temporal ordering in the auditory system. In: Pinheiro ML, Musiek FE, eds. Assessment of Central Auditory Dysfunction. Baltimore: William and Wilkins 1985:219-38.

20 Tabira T, Tsuji S, Nagoshima T, et al. Cortical deafness in multiple sclerosis. J Neurol Neurosurg Psychiatry 1981;44:433-36.

21 Wohlfart G, Lingren A, Jernelius B. Clinical picture and morbid anatomy in a case with "pure word deafness". J Nerv Ment Dis 1952;116:818-27.

22 Tanaka Y, Taquchi K, Sakabe N, et al. Pure auditory agnosia associated with alteration of voice and personal character. Folia Phoniat 1964;17:185-94.

23 Klein R, Harper J. The problem of agnosia in light of a case of pure word deafness. J Ment Sci 1956;102:112-20.

24 Earnest MP, Monroe PA, Yarnell PR. Cortical deafness: Demonstration of the pathologic anatomy by CT scan. Neurology 1977;27:1172-5.

25 Hemphill RE, Stengel E. A study on pure word-deafness. J Neurol Neurosurg Psychiatry 1940;3:251-62.

26 Shoumaker RD, Ajax ET, Schenkenberg T. Pure word deafness (Auditory verbal agnosia). Dis Nerv Syst 1977;38:213-99.

27 Albert ML, Sparks R, von Strockert T, et al. A case study of auditory agnosia: Linguistic and non-linguistic processing. Cortex 1972;8:427-43.

28 Michel F, Martin MM, Peronnet F. A propos d'un cas clinique de surdite verbale. Lyon Med 1976;236:691-8.

29 Chan JL, Hsi MS. Auditory agnosia-a case report. Taiwan I Hsueh Hui Tsa Chih 1983;7:718-23.

30 Sidtis JJ. Music, pitch perception, and the mechanism of cortical hearing. In: Gazzaniga M, ed. Cognitive Neuroscience. 1984: 91-114.

31 Quensel F, Pfeifer RA. Ein Fall von reiner sensorischer Amusie. Ztschr Neurol Psychiatr 1923;81:311-30.

32 Reinhold M. A case of auditory agnosia. Brain 1950;73:203-23.

33 Parving A. Solomon G, Elberling C, et al. Middle components of the auditory evoked response in bilateral temporal lobe lesions. Scand Audiol 1980;9:161-7.

34 Masnetoil MMR, Messimy R, Serrotte D. Un cas de surdite centrale. Ann Otolaryngol (Paris) 1959;76:1103-5.

35 Kileny $P$. Middle latency (MLR) and late vertex auditory evoked responses (LVAER) in central auditory dysfunction. In: Pinheiro ML, Musiek FE, eds. Assessment of Central Auditory Dysfunction. Baltimore: William and Wilkins 1985:87-102.

36 Woods DL, Knight RT, Neville HJ. Bitemporal lesions dissociate auditory evoked potentials and perception. Electroencephalogr Clin Neurophysiol 1984;57:208-20.

37 Ozdamar D, Kraus N, Curry F. Auditory brainstem and middle latency responses in a patient with cortical deafness. Electroencephalogr Clin Neurophysiol 1982;53:224-30.

38 Michel F, Peronnet F, Schott B. A case of cortical deafness: Clinical and electrophysiological data. Brain Lang 1980;10:367-77.

39 Shindo M, Kaga K, Tanaka Y. Auditory agnosia following bilateral temporal lobe lesions. No To Shinkei 1981;33:139-47.

40 Rosati G, Bastiani P De, Paolino E, Prosser S, Arslan E, Artioli $M$. Clinical and audiological findings in a case of auditory agnosia. J Neurol 1982;227:21-7. 
41 LeChevalier B, Rossa Y, Eustache F. Un cas de surdite corticale epargnant en partie la musique. Rev Neurol (Paris) 1984;140: 190-201.

42 Marshall RC, Rapport BZ, Garcia-Bunuel L. Self-monitoring behavior in a case of severe auditory agnosia with aphasia. Brain Lang 1985;24:297-313.

43 Motomura N, Yamadori A, Mori E, Tamaru F. Auditory agnosia: Analysis of a case with bilateral subcortical lesions. Brain 1986;109:379-91.

44 L'Hermitte F, Chain F, Escourolle R, et al. Etude des troubles perceptifs auditifs dans les lesions temporales bilaterales (à propos de trois observations dont deux anatomo-cliniques). Rev Neurol (Paris) 1971;124:327-51.

45 Assal G, Despland PA. Presentation d'un cas d'agnosie auditive. Rev Otoneuroophtalmol 1973;45:353-55.

46 Clark WE, Russell WR. Cortical deafness without aphasia. Brain 1938:61:375-83.

47 Metz-Lutz MN, North P, Dutour P, et al. Troubles auditifs d'origine corticale. A propos de deux cas. Rev Otoneuroophtalmol 1980;52:231-8.

48 Mahoudeau D, Lemoyne J, Foncin JF, et al. Considerations sur l'agnosie auditive (à propos d'un cas anatomo-clinique). Rev Neurol (Paris) 1958;99:454-71.

49 Ziegler DK. Word deafness and Wernicke's aphasia. Arch Neurol 1952:67:323-31.

50 Ulrich G. Das Syndrom der akustischen Agnosie. Fallbericht und Versuch einer neuropsychologischen Qualifizierung. Arch Psychiat Nervenkr 1977:224:221-33.

51 Kanshepolsky J, Kelley JJ, Waggener JD. A cortical auditory disorder. Neurology 1973;23:699-705.

52 Jerger J, Lovering L, Wertz M. Auditory disorder following bilateral temporal lobe insult. Report of a case. $J$ Speech Hear 1972;37:523-35.
53 Chocolle R, Chedru FR, Botte MC, et al. Etude psychoacoustique d'un cas de "surdite corticale". Neuropsychologia 1975;13:163-72.

54 Adams AE, Rosenberger K, Winter $\mathrm{H}$, Zollner $\mathrm{CH}$. A case of cortical deafness. Arch Psychiat Nervenkr 1977;224:213-20.

55 Mendez MF. Cortical auditory disorders: Functional correlation with the auditory cortex. In: Daroff RB, Conomy JP, eds. Contributions to Contemporary Neurology: A Tribute to Joseph $M$. Foley, M.D. Boston: Butterworth (in press).

56 Lassen NA, Larsen B. Cortical activity in the left and right hemispheres during language related brain functions. Phonetica 1980;37:27-37.

57 LeMoyne J, Mahoudeau D. A propos d'un cas d'agnosie auditive avec surdite corticale associée à une dysphonie fonctionnelle. Ann Otolaryngol Chir Cervicofac 1959;76:293-310.

58 Gazzaniga MS, Glass AV, Sarno MT, et al. Pure word deafness and hemispheric dynamics: a case history. Cortex 1973;9: 136-43.

59 Nagafuchi M, Suzuki J. Auditory agnosia due to incision of splenium corporis callosi. Acta Otolaryng 1973;76:109-13.

60 Guard O, Couiller JF, Dumas R, et al. Agnosie auditive. Lyon Med 1980;243:211-317.

61 Noback CR. Neuroanatomical correlates of central auditory function. In: Pinheiro ML, Musiek FE, eds. Assessment of Central Auditory Dysfunction. Baltimore: William and Wilkins 1985:7-21.

62 Celesia GG. Organization of auditory cortical areas in man. Brain 1976;99:403-14.

63 Coslett HB, Brashear HR, Heilman KM. Pure word deafness after bilateral primary auditory cortex infarcts. Neurology 1984;34:347-52.

64 Spreen O. Benton AL, Fincham RW. Auditory agnosia without aphasia. Arch Neurol 1965;13:84-92. 